University of Nebraska - Lincoln

DigitalCommons@University of Nebraska - Lincoln

Faculty Publications, Department of Child, Youth, and Family Studies

Child, Youth, and Family Studies, Department of

2021

Mealtime emotional climate and child health: A systematic review

Jasmin Smith

Jaclyn A. Saltzman

Dipti Dev

Follow this and additional works at: https://digitalcommons.unl.edu/famconfacpub

Part of the Developmental Psychology Commons, Family, Life Course, and Society Commons, Other Psychology Commons, and the Other Sociology Commons

This Article is brought to you for free and open access by the Child, Youth, and Family Studies, Department of at DigitalCommons@University of Nebraska - Lincoln. It has been accepted for inclusion in Faculty Publications, Department of Child, Youth, and Family Studies by an authorized administrator of DigitalCommons@University of Nebraska - Lincoln. 


\title{
Mealtime emotional climate and child health: A systematic review
}

\author{
Jasmin A. Smith, ${ }^{1}$ Jaclyn A. Saltzman, ${ }^{2}$ and Dipti A. Dev ${ }^{1}$
}

1 Department of Child, Youth and Family Studies, University of Nebraska-Lincoln

2 The MITRE Corporation

Corresponding author - Dipti Dev, 255 Louise Pound Hall (LPH), 512 N 12th St, Lincoln, NE 68588-0366, United States of America.E-mail address: ddev2@unl.edu

\begin{abstract}
Background: Positive mealtime emotional climate (MEC) has been linked to better nutrition, psychosocial, literacy and academic outcomes, and fewer behavior problems. However, MEC has been defined in a variety of ways across studies, limiting the ability to synthesize findings and plan future research.

Objective: To identify which child characteristics are associated with MEC and to determine how previous studies have measured MEC.

Methods: We searched three databases (1980-2020) for peer-reviewed articles measuring MEC. Inclusion criteria required at least one child-level outcome related to physical, nutritional, or developmental health; children aged 0-18 years old; and quantitative data using cohort, case-control, intervention, or experimental designs. We used a previously published taxonomy to categorize child/adolescent characteristics as correlates, non-correlates, unclear, or as having insufficient evidence, according to the amount of evidence linking them to MEC. Additionally, we extracted data about the measures and definitions of MEC from each included article.
\end{abstract}

Published in Eating Behaviors 44 (2022) 101582

doi:10.1016/j.eatbeh.2021.101582

Copyright (C) 2021 Elsevier Ltd. Used by permission.

Submitted 26 April 2021; revised 19 September 2021; accepted 17 November 2021;

published 24 November 2021 
Results: Out of 668 unique studies identified in the initial search after duplicates removed, 14 met inclusion criteria, and only three used the same measure of MEC. Healthful dietary intake, disordered eating behaviors, and weight/BMI were categorized as correlates of MEC, but links to unhealthy dietary intake are unclear. Several characteristics (e.g. temperament, academic success) were examined in one study only.

Conclusions: Future research should examine the relationship between MEC and child psychosocial child outcomes and utilize a preschool age group. These findings aid in conceptualizing how MEC has been defined and measured and illuminate the importance of MEC on children's health.

Keywords: Mealtime emotional climate, Child health, Dietary intake

\section{Background}

Mealtime emotional climate (MEC) has previously been defined as the level of positive and negative interpersonal interactions and emotional expression during mealtimes (Fosco \& Grych, 2013; Hughes et al., 2011; Saltzman et al., 2017). A negative mealtime emotional climate can involve expressions of negative emotion, hostile interpersonal dynamics, food lecturing/moralizing, frequent silence, food controlling, indulgence (Berge et al., 2014; Saltzman et al., 2017). A positive mealtime emotional climate can involve expressions of positive emotion, warm or nurturing interpersonal dynamics, high levels of group cohesion or enjoyment, and positive communication about food (Berge et al., 2014; Saltzman et al., 2017).

Mealtime emotional climate has been linked previously to certain health characteristics in children. For example, in a small longitudinal study that observed meals in the family home, mother-child dyads that expressed mostly positive emotions at meals had children who ate more healthy foods than children in dyads who expressed about equal levels of positive and negative emotion in surveys 6-months later (Saltzman et al., 2017). However, another study found a significant correlation of positive MEC with weight status but not healthful eating (Tremblay \& Rinaldi, 2010). Another study found that families with a more negative mealtime emotional climate (characterized by higher levels of hostility) had children who were more likely to be overweight (Berge et al., 2014). Additionally, parents of overweight/ 
obese children were found to be more likely to engage in hostility and to lecture about food which contributes to a negative mealtime emotional climate (Berge et al., 2014).

Although these findings compellingly point to a possible correlation between MEC and children's weight-related health, the breadth of the aforementioned findings underscore the need to systematically review the literature to determine significant correlates of MEC. Further, there is a need for a consistent operational definition of MEC and how it is measured. Studies often either failed to define MEC as a whole or used constructs in the measure to describe and create a definition of MEC. For example, Czaja et al. (2011) operationalized MEC by evaluating parent-child interactions in a naturalistic home setting during family mealtimes (Czaja et al., 2011). In contrast, a study conducted by Zeller et al. (2007) operationalized MEC by using a self-reported questionnaire to analyze mealtime challenges and positive mealtime interactions (Zeller et al., 2007). These disparate operational definitions highlight the first of two significant gaps in the current literature. Although each approach to defining and measuring MEC has its merits, it is important for the field to coalesce on a consistent operational definition if we are going to continue examining-and perhaps ultimately intervening on-associations between emotions at mealtimes and health. However, it would be unnecessary to operationalize the MEC construct if it were not reliably associated with outcomes of interest, which highlights the second clear gap in the literature. There has not yet been a synthesis of existing literature to determine whether future studies are needed to explore the relationship between MEC and child characteristics such as temperament, physical health, and disordered eating behaviors are warranted. Although much of the research described above is focused on relationship of MEC with child weight-related correlates, it is unclear whether MEC is consistently associated with these potential correlates, or whether MEC may be linked to other child characteristics. Therefore, to address these gaps, the current study aims to address the following research questions: (1) what are the child/adolescent level correlates of MEC?; and (2) how have researchers measured MEC in past studies? 


\section{Methods}

\subsection{Protocol registration}

This review focuses on MEC and child/adolescent nutrition status, physical status, and developmental outcomes. The protocol was registered on the International Prospective Register of Systematic Reviews (PROSPERO; see Smith, Saltzman, \& Dev, 2019). PROSPERO is used to register and maintain a record of systematic reviews in order to avoid duplication of studies and reduce reporting bias (National Institute for Health Research, 2019). Guidelines for the Preferred Reporting Items for Systematic Reviews and Meta-Analysis (PRISMA; Moher et al., 2009) system were utilized to improve the reporting quality. Both PROSPERO and PRISMA were used to ensure transparency throughout the process, organize the search, and present findings.

\subsection{Eligibility criteria}

Studies were included if they met all of the following criteria: (a) measured emotional climate during mealtime; (b) included at least one measure of child nutrition, child physical health, or a child developmental outcome; (c) measured emotion in more than one person; (d) included typically developing children or a control group with typically developing children; (e) included parents that were healthy or free of disease; (f) published in a peer-reviewed journal; (g) published in English or an English translation was available; $(\mathrm{h})$ conducted with humans; (i) published between January 1, 1980, and April 30, 2020; and (j) included human children and adolescents from birth to age 18 . Studies included were quantitative cohort (cross-sectional or longitudinal), case-control (cross-sectional or longitudinal), intervention (randomized or nonrandomized) or experimental designs. Studies were excluded if, in case-control studies or interventions, the sample size was $\mathrm{n} \leq 10$ per group or $\mathrm{n} \leq 20$ total, or in cohort studies, the sample size was $\mathrm{n} \leq 20$.

\subsection{Search strategy}

A wide search of published literature was conducted in the following databases: PsycINFO, PubMed, and ERIC (Education Resources 
Information Center). Databases were selected based on the feedback of an expert librarian because they yielded the most relevant articles based on our topic of interest. Articles were searched for publication between January 1, 1980 and April 30, 2020 with key terms related to MEC and child outcomes. As there is a lack of commonality among terminology for MEC, the following search string was used to encompass emotions surrounding various mealtimes ("emotion" or "conflict" or "argument" or "atmosphere" or "climate" or "environment" or "pleasant" or "interpersonal" or "dynamics" or "routine") AND ("meal" or "mealtime" or "feed" or "dinner" or "breakfast" or "lunch" or "supper") AND ("child" or "children" or "teen" or "adolescent" or "youth" or "family") NOT ("global warming" or "climate change") NOT ("qualitative" OR "systematic review" OR "focus group"). Filters for language and document type were also applied for all databases.

\subsection{Study selection}

Two researchers used DistillerSR to independently screen a different half of the article abstracts identified through the literature search (Fig. 1). DistillerSR is an online software used to expedite the review process by increasing transparency, facilitating form creation for abstract screening and data extraction, tracking progress, providing included/ excluded reference counts, and conducting kappa interrater reliability scoring (Evidence Partners, 2019). Of the 668 abstracts reviewed, $20 \%$ were screened by the first and third authors to ensure the inclusion/exclusion criteria were being applied consistently. Inconsistencies were then discussed and resolved by consensus. After abstracts were reviewed and 529 excluded, 66 full-text articles were screened by the first author and comprehensively assessed against the inclusion/exclusion criteria and data extraction and coding was completed.

\subsection{Data extraction and coding}

A standardized form was utilized to extract and record the following information about the studies selected for inclusion: sample size, sample characteristics (Race/ethnicity, age, gender breakdown, SES, weight status, etc.), operational definition of mealtime emotional climate, research method (study design, measure), potential correlates, analysis, results, and conclusions (association, no association). 
Correlates were identified for the included studies. If three or more of the studies assessing a construct found consistent results, the construct was classified as a "non-correlate" (no association) or a "correlate" (positive or negative associations). If three or more of the studies assessing a construct had inconsistent results, the construct was classified as "unclear." However, if only two studies assessed a construct then it was not classified due to inadequate evidence but was instead labeled "N/A.". This method of classifying correlates is consistent with previously published taxonomy to categorize child/adolescent characteristics as correlates, non correlates, unclear, or as having insufficient evidence, according to the amount of evidence linking them to the study variable (Jacobi et al., 2004; Kraemer et al., 1997; Saltzman \& Liechty, 2016).

\subsection{Risk of bias assessment}

The first author independently assessed each article for risk of bias using the National Heart, Lung, and Blood Institute's (NHLBI's) quality assessment tools (National Heart, Lung, 2020). A second researcher then independently assessed risk of bias using NHLBI's quality assessment tool for half of the articles. There was a consensus of $81 \%$ between the two researchers. Disagreements were resolved via consensus. Based on the questions from the NHLBI's quality assessment, 4 key questions were identified that could pose a fatal risk to the study and impact the results of interest based on the answer to the following four questions (a) was the research question or objective in this paper clearly stated; (b) were the exposure measures (independent variables) clearly defined, valid, reliable, and implemented consistently across all study participants; (c) were the outcome measures (dependent variables) clearly defined, valid, reliable, and implemented consistently across all study participants; (d) were key potential confounding variables measured and adjusted statistically for their impact on the relationship between exposure(s) and outcome(s)? Questions were chosen to identify the potential for posing a fatal risk to the study if they directly measured an aspect related to the study aims. This allowed for examining how the study's risk of bias directly impacted the aims. If the study received a yes for all identified key questions or only one no or not reported then the study was classified as low risk. 


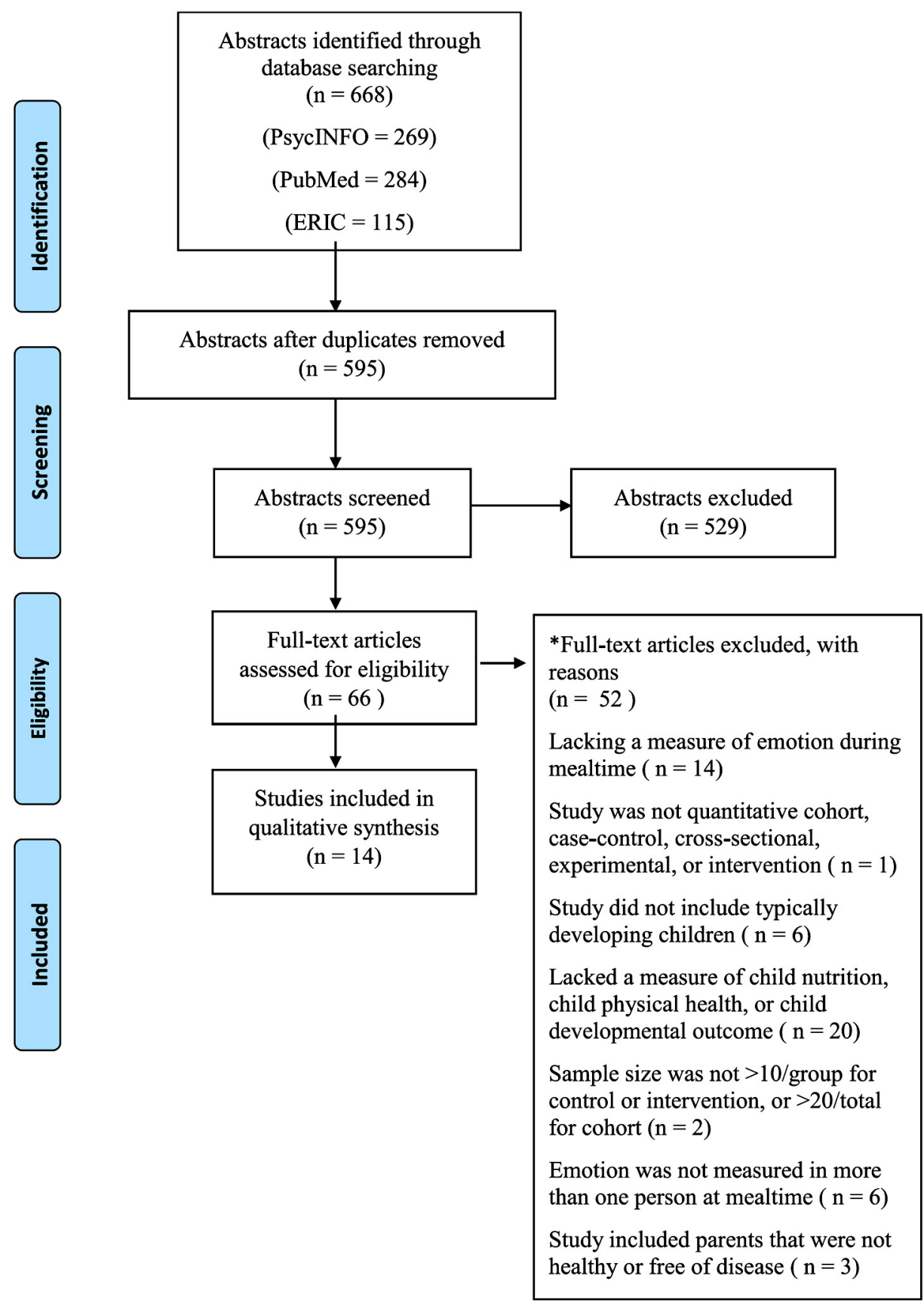

Fig. 1. Flow chart of article search and selection process following the Preferred Reporting Items for Systematic Reviews and Meta-Analyses (PRISMA) guidelines (www.prisma-statement.org).

*Some studies had multiple reasons for exclusion. 
If the study received a no or not reported for two or more identified key questions the study was classified as moderate risk. If the study received a no or not reported for three or more questions the study received a high-risk categorization.

\section{Results}

For this review 668 articles were identified through PsycINFO ( $\mathrm{n}=$ 269), PubMed $(n=284)$, and ERIC $(n=115)$. Once duplicates were removed, 595 abstracts were screened. Sixty-six full-text articles were screened, and 14 articles were included in the qualitative synthesis. Of the studies included in the review $(n=14)$, eleven were cross-sectional and three were longitudinal. One study was experimental (this study was longitudinal/cross-sectional) and thirteen were observational. Of the 14 articles includes, 6 of the studies were conducted outside of the United States of America (see Table 1).

\subsection{Aim 1: correlates of MEC and health/developmental outcomes}

Findings are summarized in Table 2.

\subsubsection{Dietary intake}

Three studies of the 14 examined associations between MEC and healthful dietary intake. All three studies found an association and had low risk of bias. Additionally, healthful dietary intake was classified as a correlate of positive MEC. Of the studies finding an association between MEC and unhealthful dietary intake, two had low risk of bias and one had moderate risk of bias. Two studies found a positive association between MEC and unhealthful dietary intake (Fiese et al., 2015; Harbec \& Pagani, 2018), and one found no association (Saltzman et al., 2017). One study reported the amount of time spent not engaging in the mealtime being negatively associated with consumption of carrots, pizza, and diet soda and positively associated with the consumption of cookies and sugary sodas (Fiese et al., 2015). Higher family environment quality during mealtime was positively associated with less soft drink consumption (Harbec \& Pagani, 2018). 


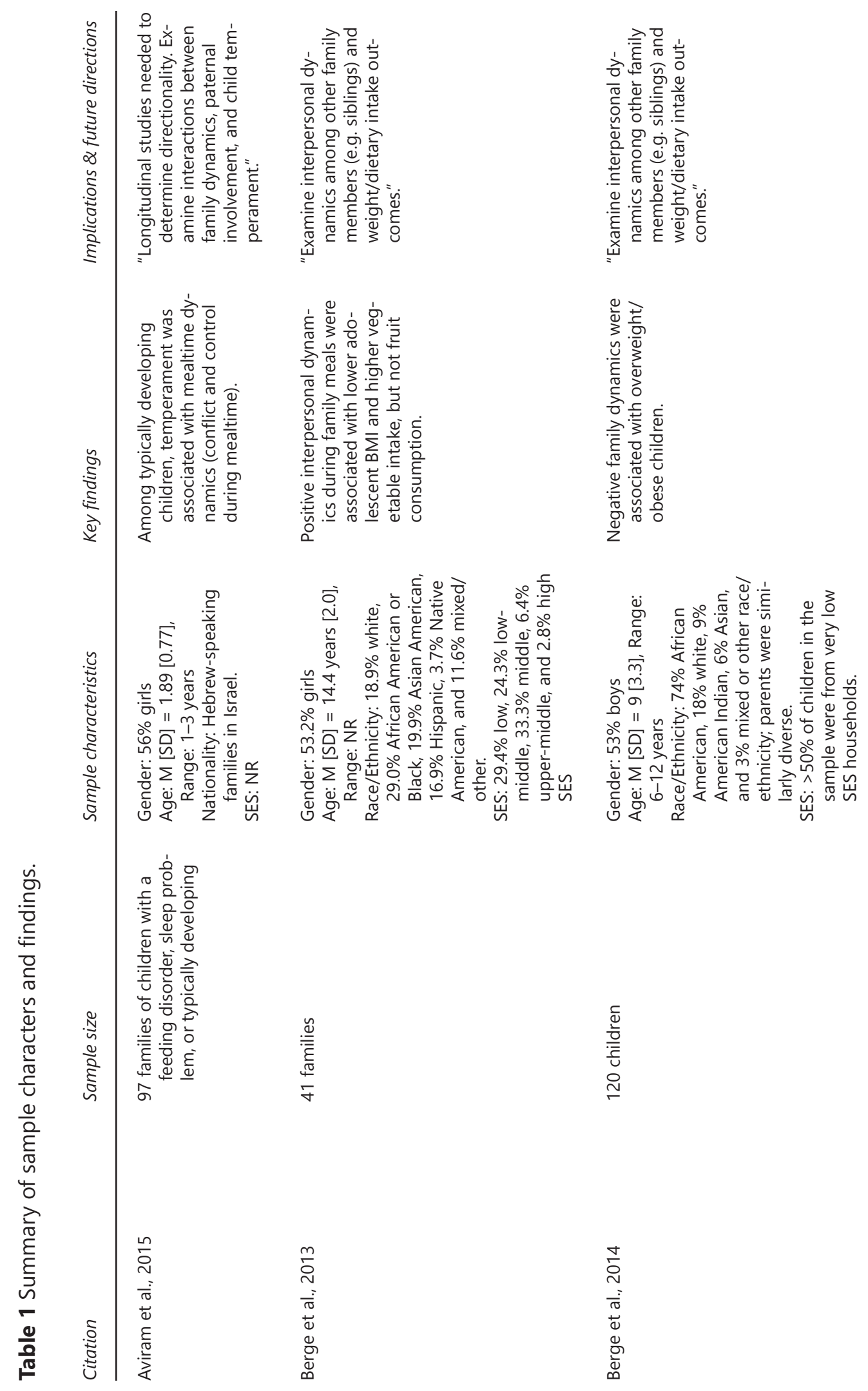




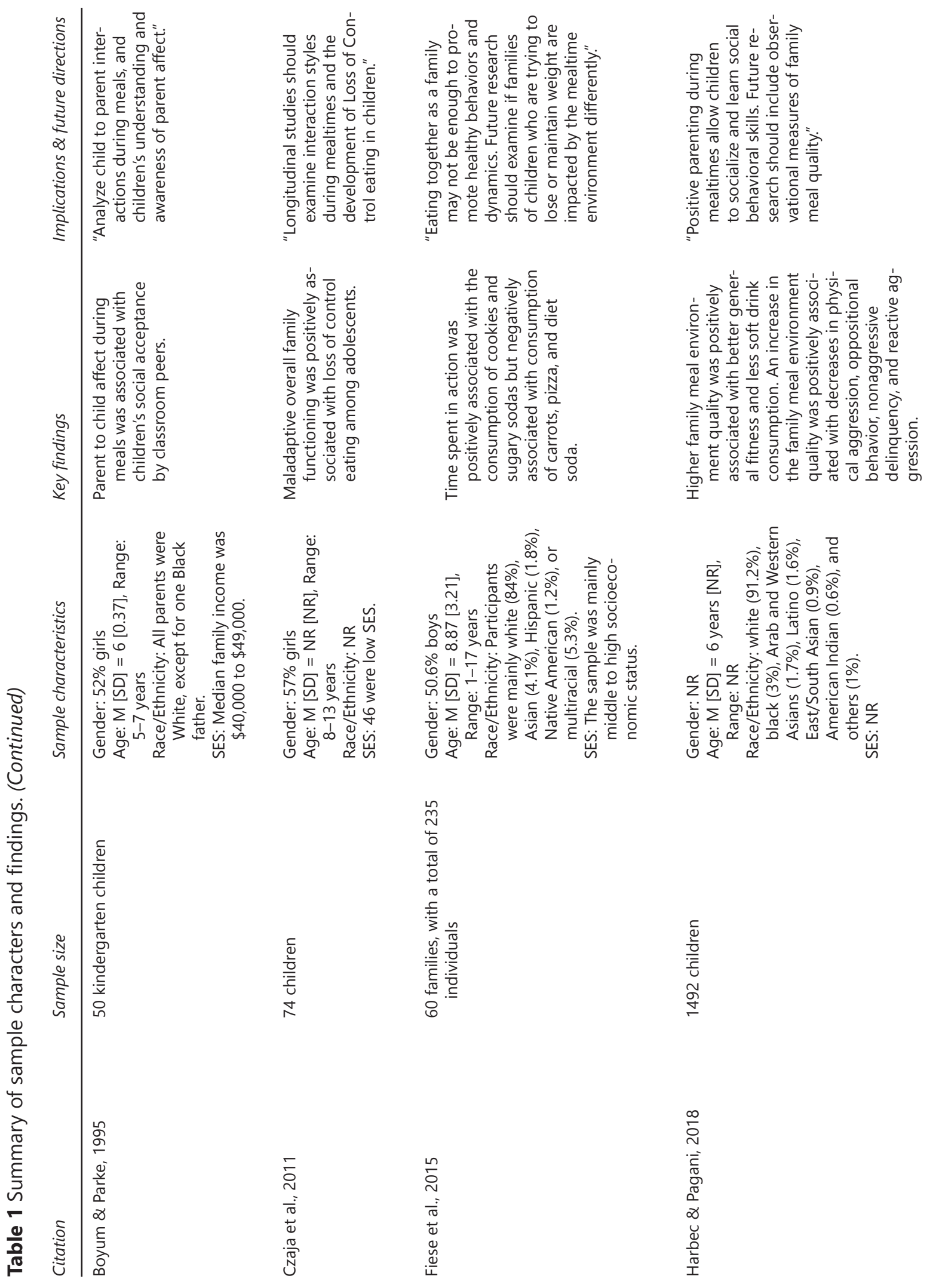




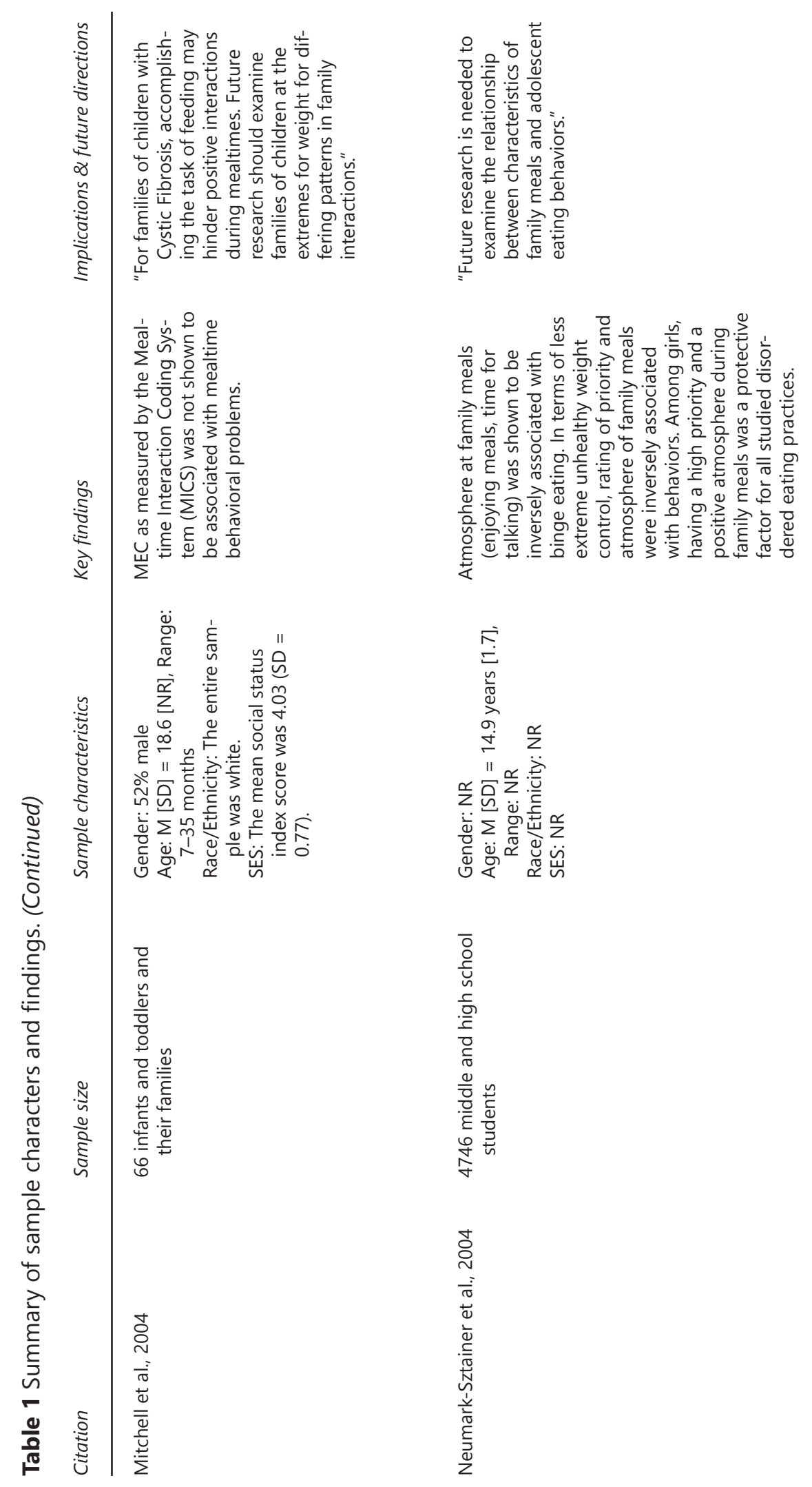




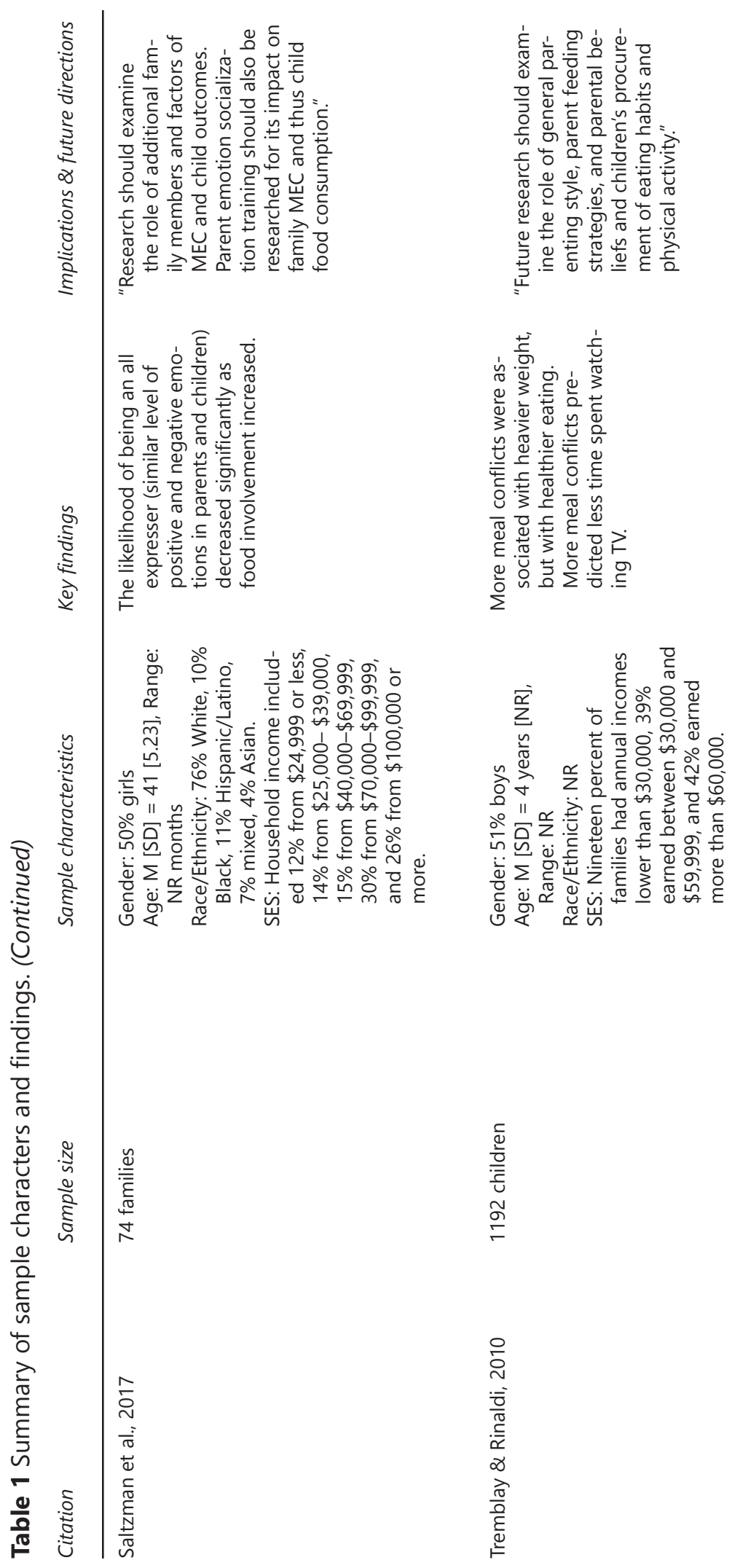




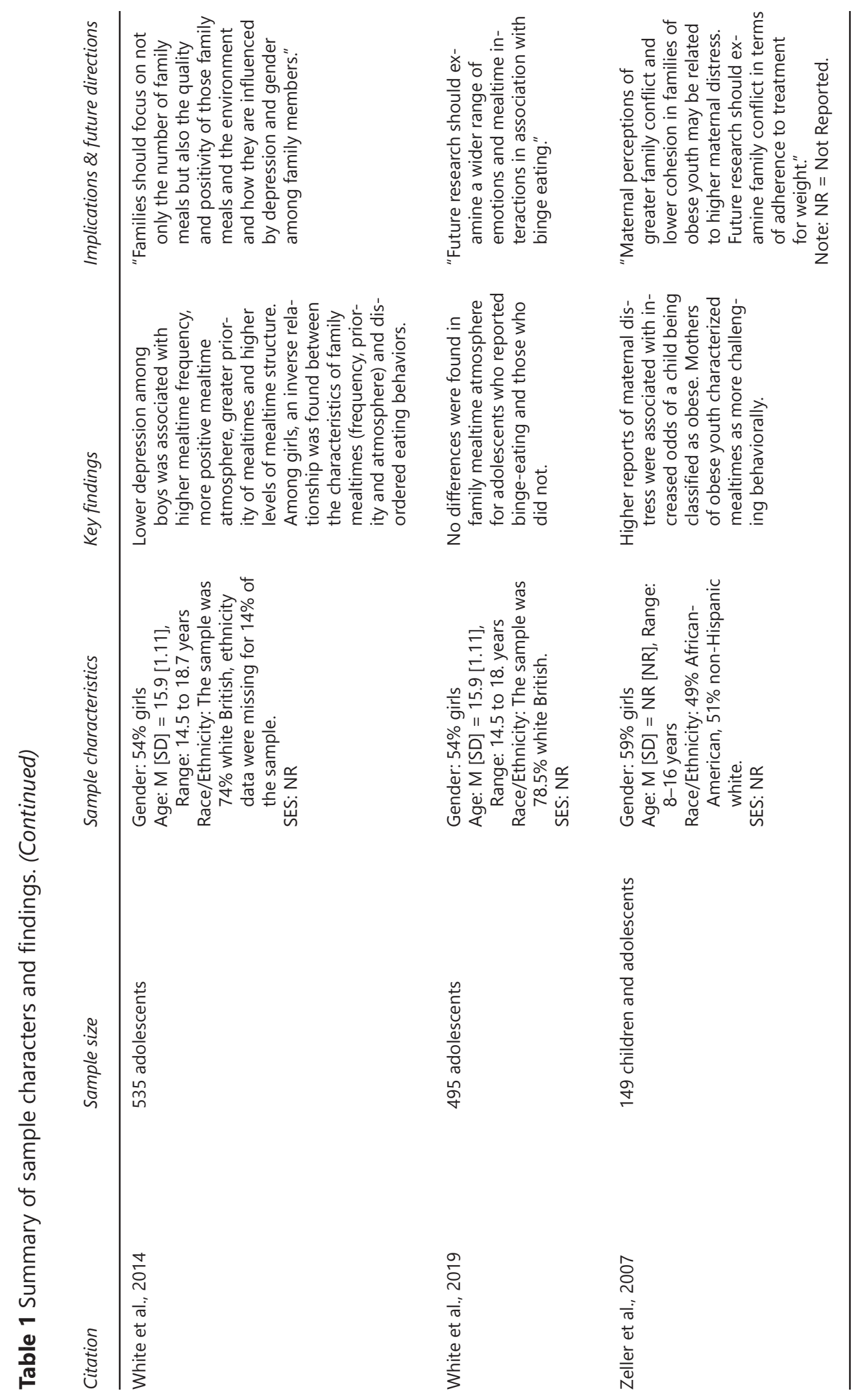




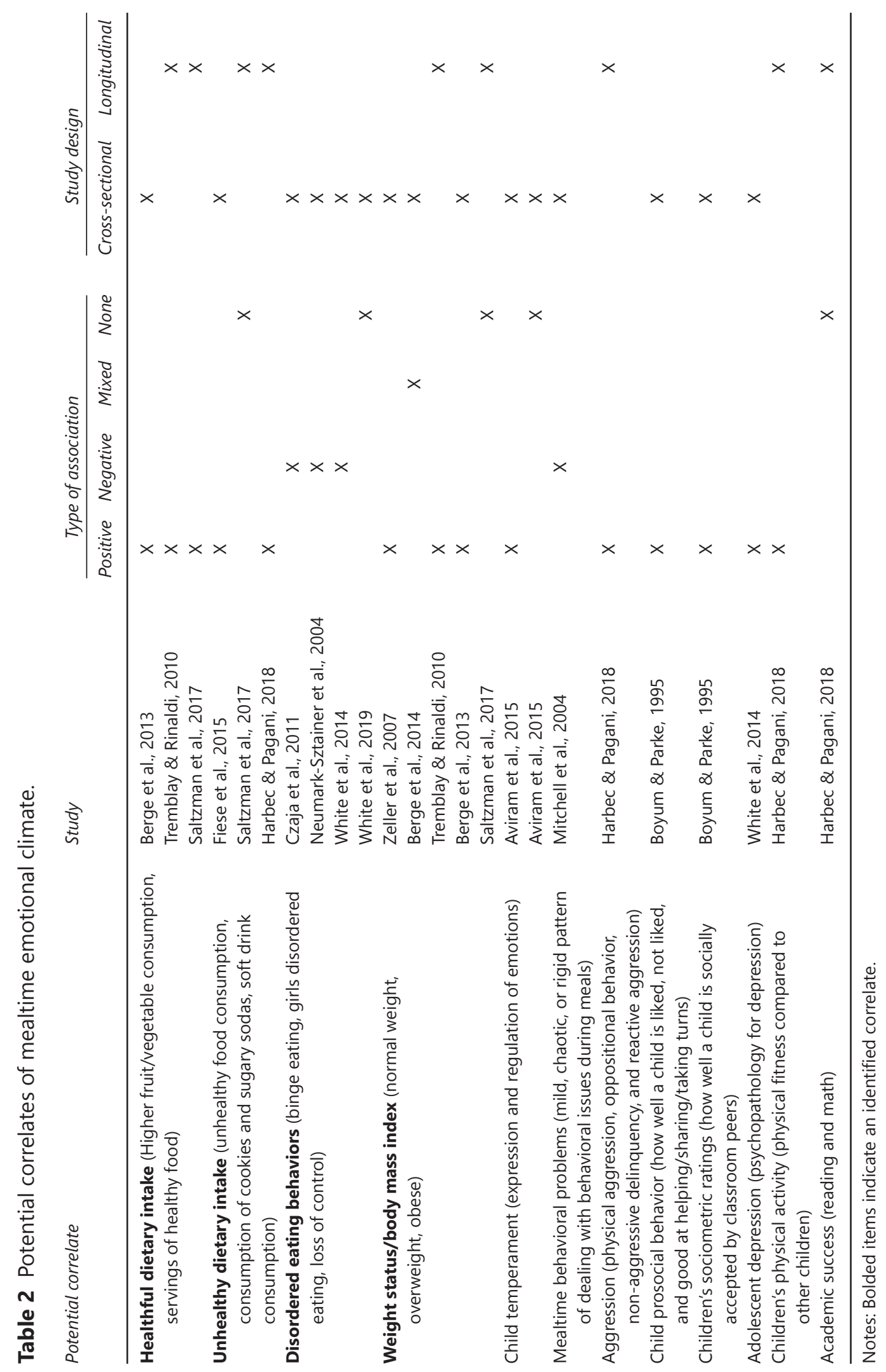


However, Saltzman et al. (2017) found no association between families expressing equal amounts of positive and negative emotions during mealtimes and unhealthy food consumption by children. As such, the relationship between unhealthy dietary intake and mealtime emotional climate was classified as unclear.

\subsubsection{Body mass index/weight status}

Five studies examined the relationship of MEC with body mass index (BMI) among children. Of those studies, five had low risk of bias. Four studies found an association between MEC and BMI (Berge et al., 2013; Berge et al., 2014; Tremblay \& Rinaldi, 2010; Zeller et al., 2007), and one study found no association (Saltzman et al., 2017). BMI was classified as a correlate of MEC. Three studies examined correlations between MEC and weight status. Altogether, five unique studies examined an association between weight status or BMI and MEC. Of these, three found a positive association (Berge et al., 2013; Tremblay \& Rinaldi, 2010; Zeller et al., 2007), one had mixed findings (Berge et al., 2014), and one found no associations (Saltzman et al., 2017). Thus, in our review, weight status/BMI were also classified as correlates of MEC.

\subsubsection{Disordered eating behaviors}

Four studies examined associations between MEC and disordered eating behaviors, and three found significant correlations. Of the four studies examining disordered eating, all had low risk of bias. Generally, more negative MEC was associated with greater levels of disordered eating, particularly among girls and adolescents. Czaja et al. (2011) found that maladaptive overall family functioning was associated with more loss of control eating among adolescents. However, interpersonal involvement and communication patterns were negatively associated with loss of control eating (Czaja et al., 2011). One study found that a positive atmosphere during family meals was negatively associated with unhealthy eating and weight control behaviors including binge eating, and use of diet pill, laxatives, and diuretics (NeumarkSztainer et al., 2004). White et al. (2014) found high frequency, high priority, and positive atmosphere of family meals to be negatively associated with disordered eating behaviors among adolescent girls. However, one study found no association between binge-eating behaviors and MEC (White et al., 2019). Therefore, disordered eating behaviors were classified as correlates of MEC. 


\subsubsection{Other correlates}

Several other potential correlates were examined by only one study each. Among these studies, 4 had low risk of bias and 1 had moderate risk of bias. These correlates include: child temperament (Aviram et al., 2015), mealtime behavioral problems (Mitchell et al., 2004), aggression (Harbec \& Pagani, 2018), prosocial behavior (Boyum \& Parke, 1995), sociometric ratings (Boyum \& Parke, 1995), depression (White et al., 2014), physical activity (Harbec \& Pagani, 2018), and academic success (Harbec \& Pagani, 2018). Findings are summarized in Table 2 , but there was not enough evidence to evaluate the body of literature relevant to these potential correlates.

\subsection{Aim 2: measures of MEC}

Definitions and measures are summarized in Table 3. Regarding the definition of MEC, across studies, definitions focused generally on dyadic interactions during mealtimes, mealtime atmosphere, conflict during or because of meals, emotional expression, or communication during meals. Thus, to the best of our knowledge, no consistent definition or operationalization of MEC has been identified.

Regarding the measurement of MEC, eight studies measured MEC using an observational coding system and seven utilized self-report measures completed by parents or adolescents. One study utilized both an observational and self-report measure and thus was included in both counts (Harbec \& Pagani, 2018). Further, twelve studies in the current review were conducted in home-based settings, one was conducted in a laboratory-based setting, and one was conducted in both laboratory and home-based settings (see Table 3).

The measures included varying degrees and types of validity including factors analysis and intraclass correlations. Of the eight studies that used an observational coding system, three utilized the Family Mealtime Interaction Coding System (MICS) in children aged 12-17 years (Berge et al., 2013), 8-13 years (Czaja et al., 2011), and 6-36 months (Mitchell et al., 2004). Other observation coding systems utilized included: dyadically coding the affect directed by one family member to a specific partner, (children aged 5-7 years; Boyum \& Parke, 1995); the Toddler Feeding Scale (children aged 1-3 years; Aviram et al., 2015); an adapted version of the D.O.T.S. emotion coding 


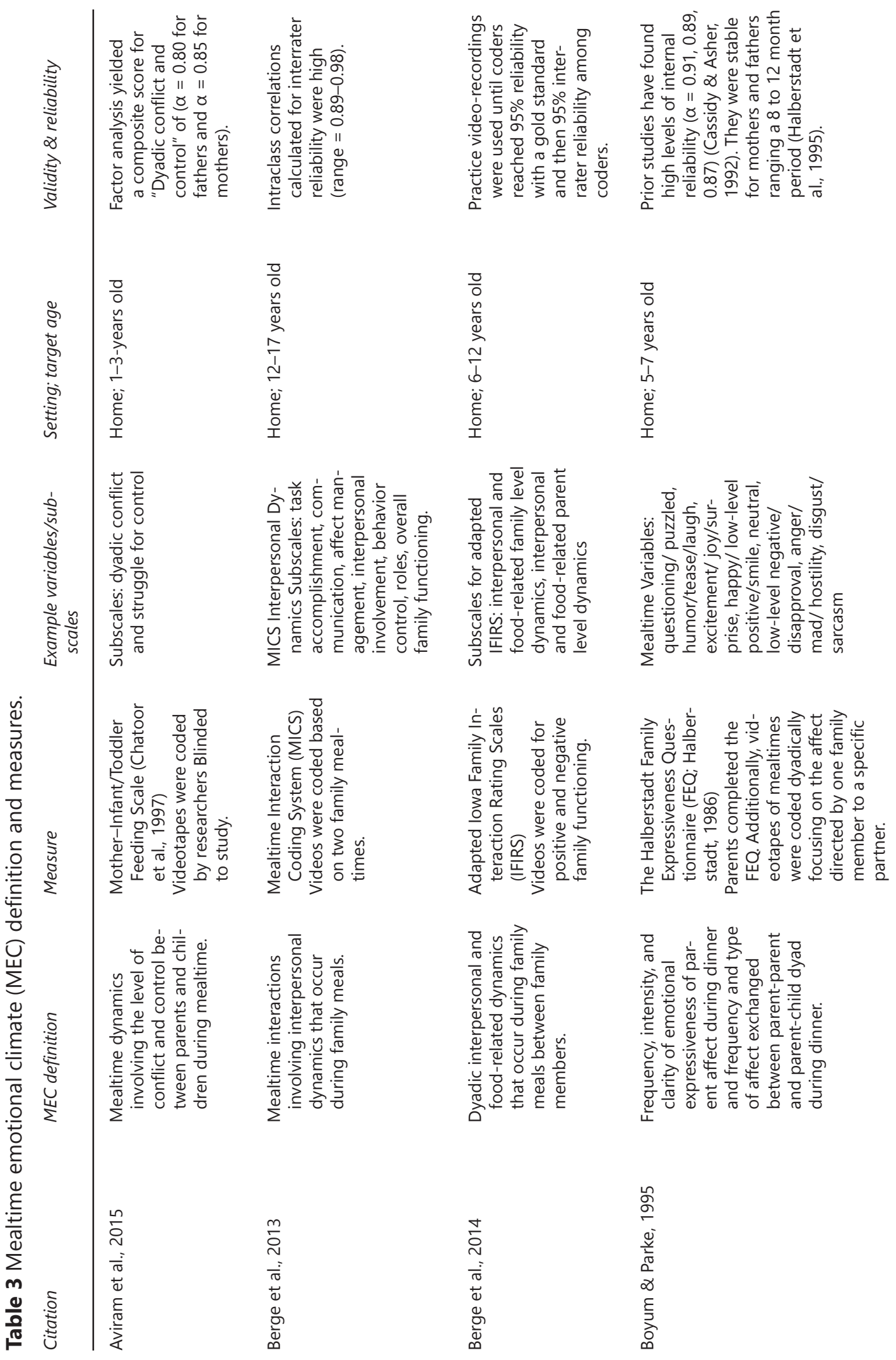




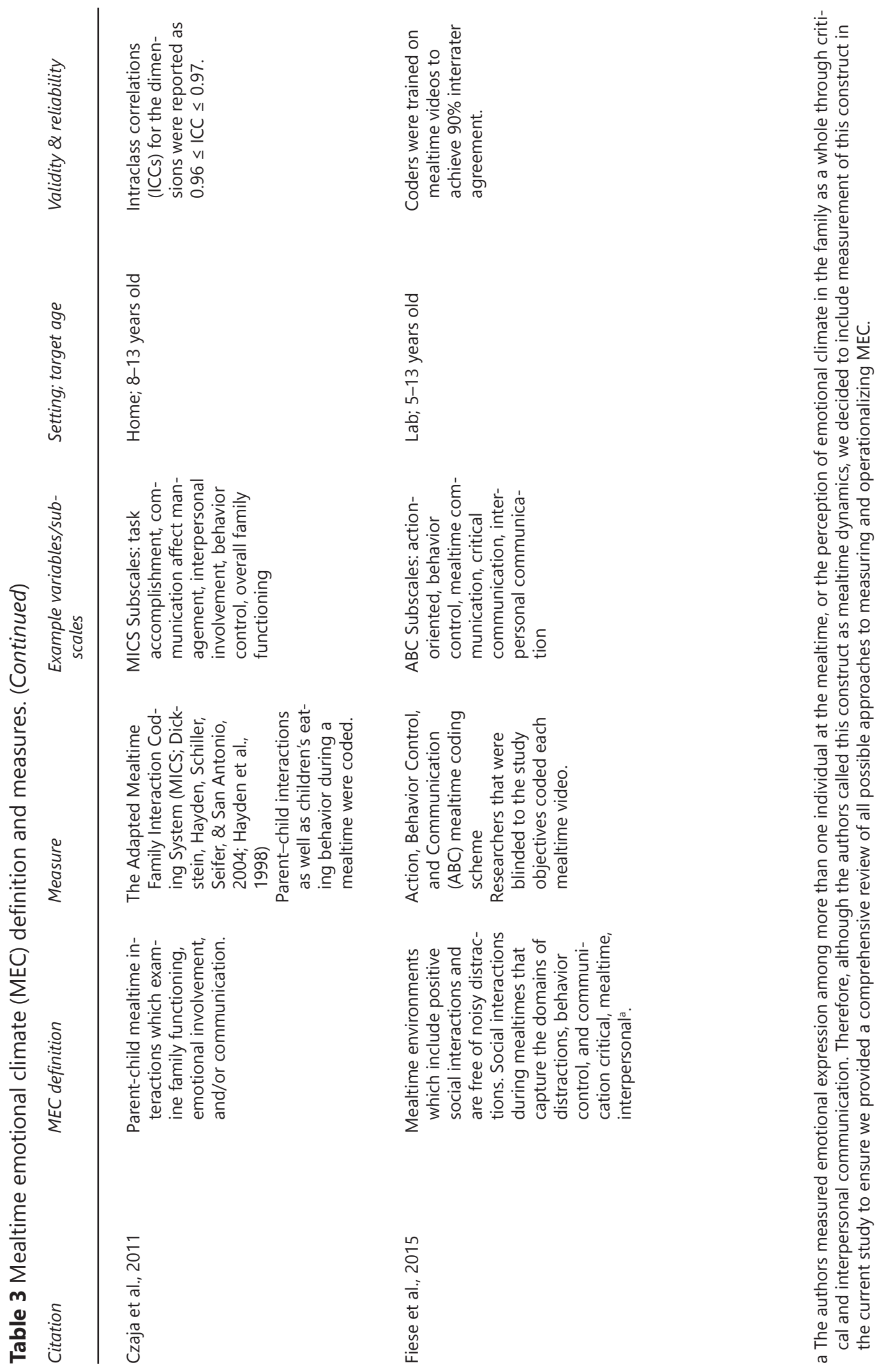




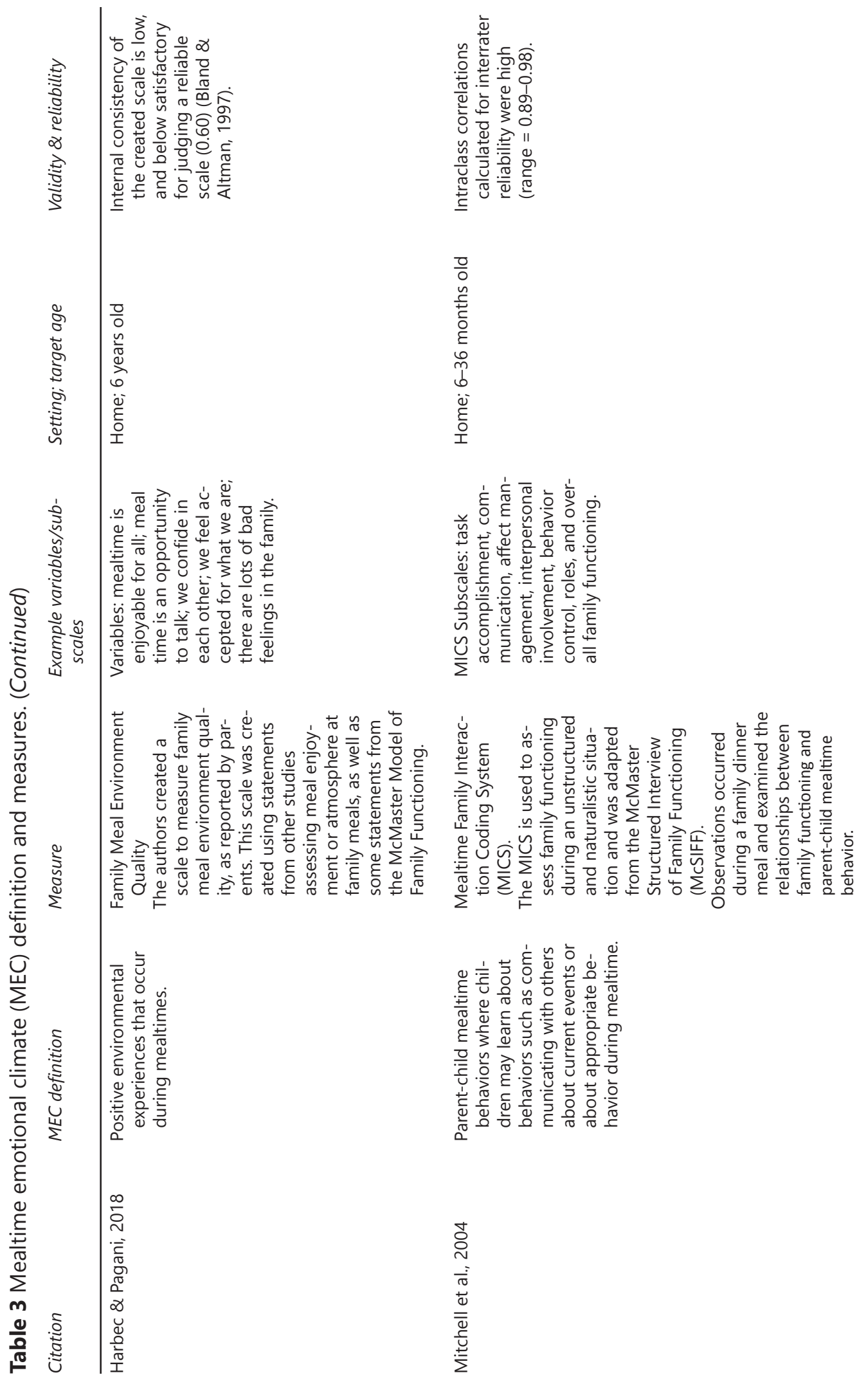



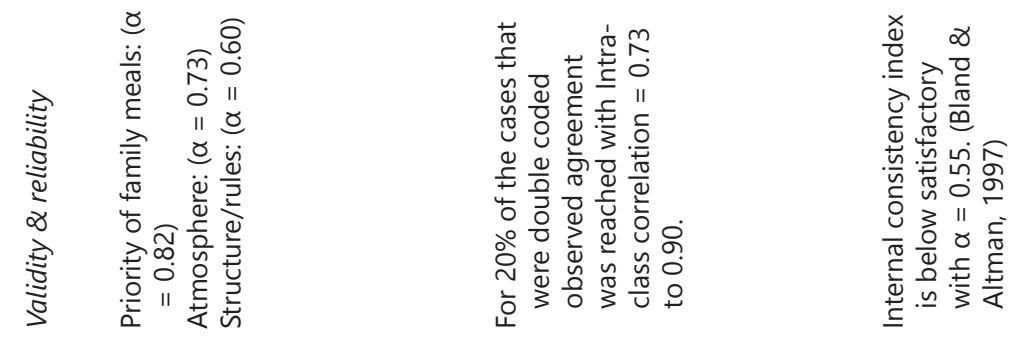

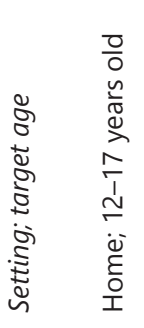
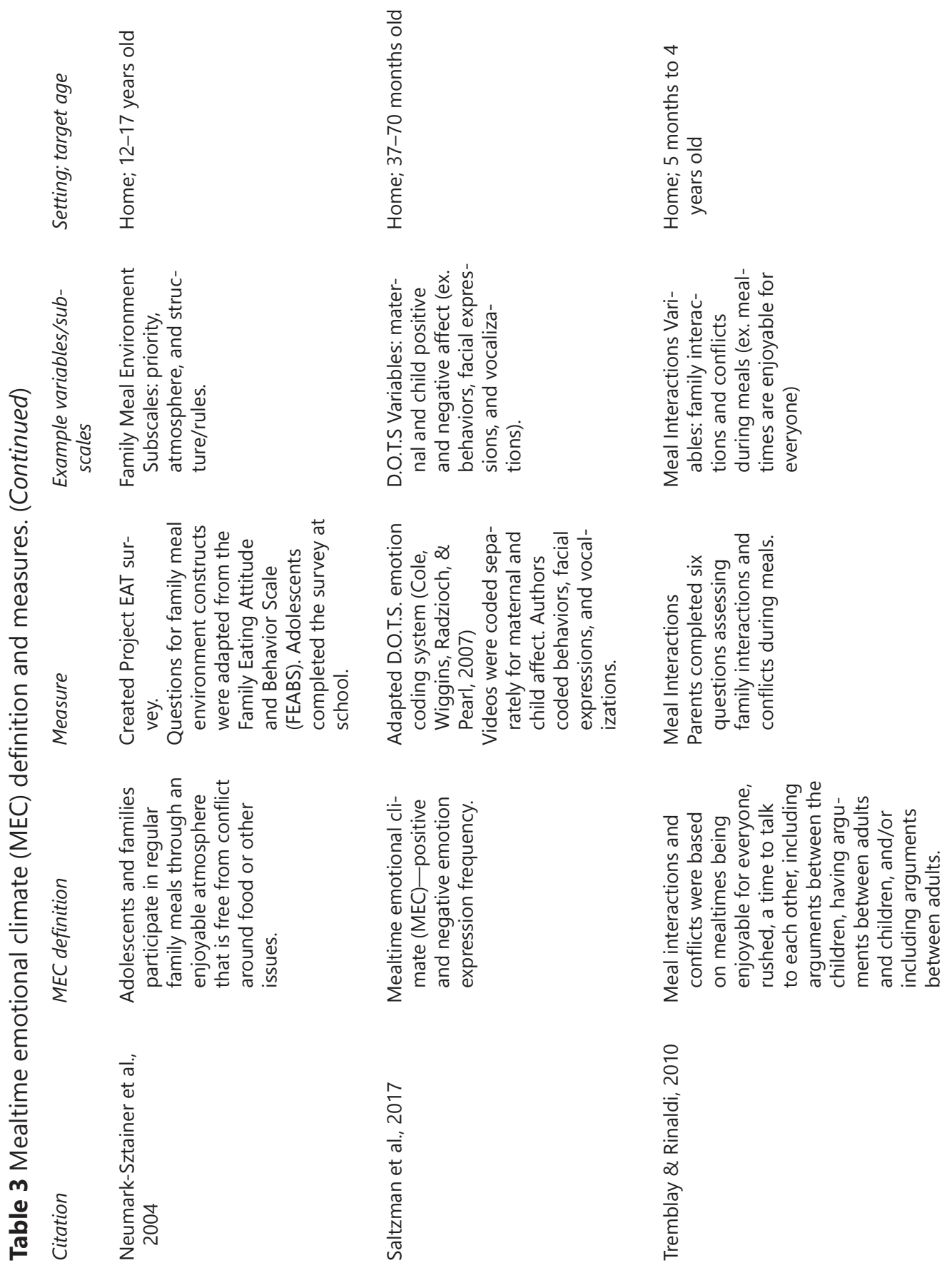


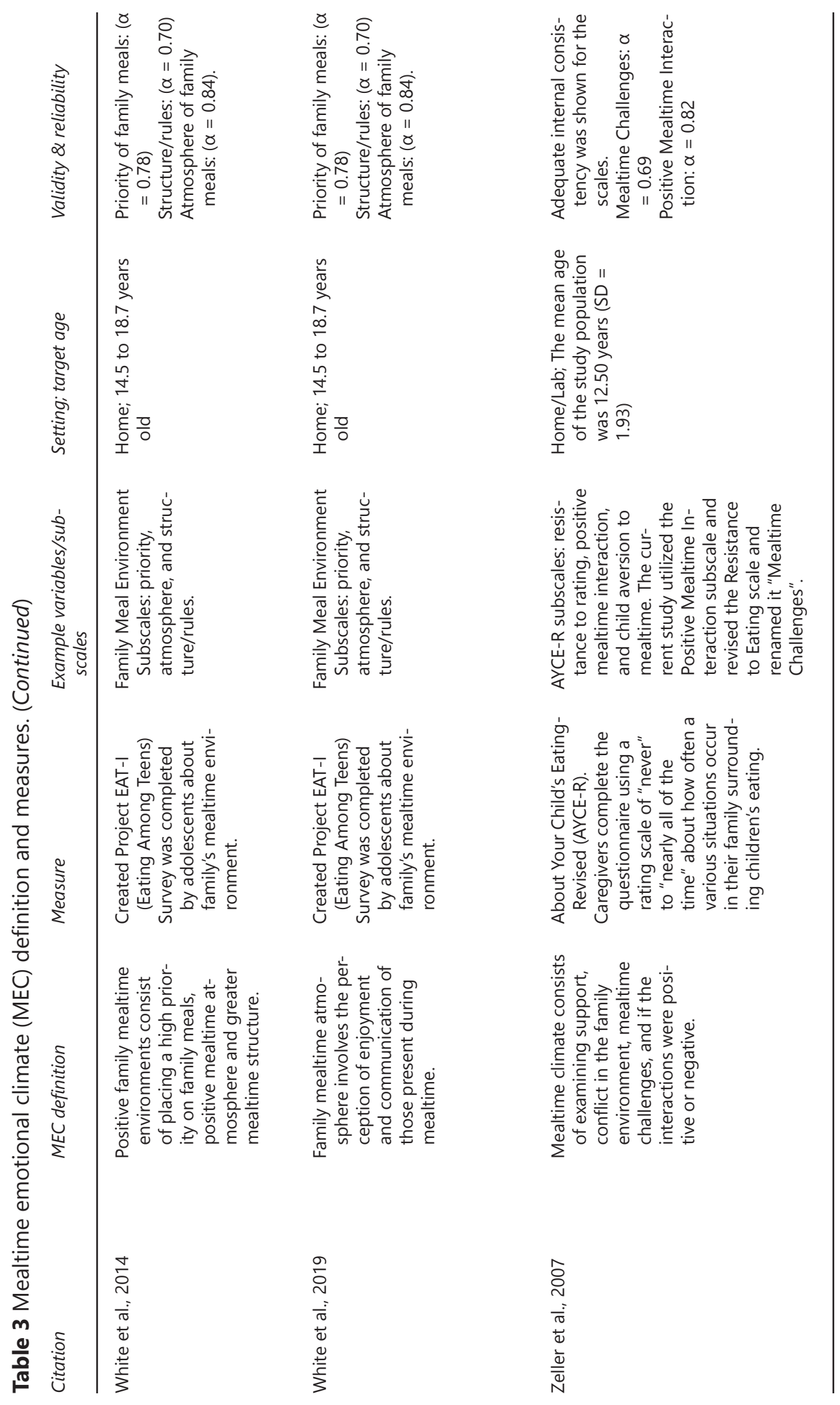


system (children aged 37-70 months; Saltzman et al., 2017); the Action, Behavior Control, and Communication (ABC) mealtime coding scheme (children aged 5-13 years; Fiese et al., 2015), and an adapted version of the lowa Family Interaction Rating Scales (IFIRS) (children aged 6-12 years; Berge et al., 2014). The MICS was the most utilized observation coding system for MEC and has been highly validated across the literature (Dickstein \& Martin, 2002; Jacobs \& Fiese, 2007; Janicke et al., 2005; Mitchell et al., 2009).

In terms of self-report measures, seven studies utilized questionnaires to measure MEC. Three studies used items from the Project EAT (Eating Among Teens) survey with adolescents aged 12-17 years (Neumark-Sztainer et al., 2004), and aged 14-18 years (White et al., 2014). One study utilized the About Your Child's Eating-Revised (AYCER) with children aged 12 years (Zeller et al., 2007). One study utilized the Halberstadt Family Expressiveness Questionnaire (FEQ) in addition to an observational measure with children aged 5-7 years (Boyum \& Parke, 1995). Two studies utilized a questionnaire completed by the parents developed as part of a larger study with children aged 6 years (Harbec \& Pagani, 2018) and aged 5 months to 4 years old (Tremblay \& Rinaldi, 2010). The most used survey to measure MEC were the items from the Project EAT survey, but two studies came from the same dataset. Otherwise, there was no commonality in the type of questionnaire used across studies.

\section{Discussion}

This study aimed to understand which child or adolescent characteristics were associated with MEC, and how MEC has been measured across studies. Overall, a positive association was found between MEC and dietary intake and MEC and weight status/BMI. A negative association between MEC and disordered eating behaviors was found. However, more research is needed to understand the relationship between MEC and developmental outcomes such as aggression, temperament, depression, and academic success. Additionally, to the best of our knowledge, no consistent definition of operationalization of MEC has been identified.

Overall, positive MEC was associated with healthful dietary intake (e.g., higher fruit and vegetable consumption) and less unhealthy food 
intake (e.g. less high sugar foods and drinks consumption) among children and adolescents. Notably, associations between healthful dietary intake and MEC were consistent across cross-sectional and longitudinal studies in preschool aged children and adolescents, and in American and Canadian populations. Two of the studies Tremblay and Rinaldi (2010) and Saltzman et al. (2017), used a longitudinal design, suggesting that positive MEC may have long term implications for children's dietary intake. To the contrary, negative MEC was associated with unhealthful dietary intake where two studies found positive association (Fiese et al., 2015; Harbec \& Pagani, 2018) and one found no association (Saltzman et al., 2017). However, the two finding an association between MEC and dietary intake were done with schoolaged children and used a cross-sectional and longitudinal study design while the one finding no association was conducted with preschoolers and used a longitudinal design. During the toddler and preschool age range, mealtimes may be more stressful for caregivers and children. Specifically, toddlers and preschoolers may seek more independence and therefore refuse to eat at the table, leave the table before the mealtime is over, or refuse to eat which can make observing a positive MEC more difficult if children do not participate in mealtimes (Tynan et al., 2009). As children age and reach school age they have more self-control and social skills around eating (Fiese \& Schwartz, n.d.). Moreover, families of older children may expect more structure such as establishing a regular mealtime routine, having a regular family meal where the child eats at the table, or avoid screens and other distractions during mealtime (Fiese et al., 2006; Tynan et al., 2009). These mealtime routines and rituals for older children may help them establish concepts related to MEC such as communication, bonding, affect management, and interpersonal involvement (Fiese \& Schwartz, n.d.; Fiese et al., 2006; Tynan et al., 2009). Also, creating a positive MEC involves setting expectations for behavior and the setting of mealtimes in addition to creating routines and consistency (Fiese \& Schwartz, n.d.; Eisenberg et al., 2004). These concepts may be hard to grasp and implement with toddlers when compared to schoolaged children. However, as infants and toddlers are developing eating behaviors, they reject new foods, have food neophobia, and a preference for certain foods such as sweet and salty foods (Birch \& Fisher, 1998). These behaviors are often formed during the transition from a milk diet to an omnivore diet that occurs during early childhood (Birch 
\& Fisher, 1998). The food environment has a major role on children's food preferences and dietary intake. Caregivers often shape children's experience with food and young children tend to be influenced by and follow the example of their caregiver (Birch \& Fisher, 1998). Thus, while infants and toddlers may not be able to readily understand the need for routines and engagement with adult caregivers for a positive MEC, is it still important for families to practice behaviors contributing to a positive MEC with young children as they are developing their food preferences. Additionally, certain child characteristics of interest may be more targeted at specific age groups such as positive language development for preschool-aged children, academic achievement for school-aged children, and substance usage and disordered eating for adolescents. Therefore, research is needed to better understand the factors influencing MEC across different age groups.

Although consistency across study design and population variations strengthens our confidence in findings linking MEC and healthy food intake, these variations may account for some studies finding positive associations while others found none between MEC and unhealthy dietary intake. Therefore, additional studies are warranted for examining different age groups and longitudinal study design to determine the relationship between MEC and unhealthy dietary intake. Regarding the strength of the study design, the correlates currently presented should consider the study design when appropriate. The following correlates were derived from the longitudinal and cross-sectional studies: healthful dietary intake, unhealthy dietary intake, and weight status/BMI. The correlate disordered eating behaviors was derived from cross-sectional studies. Future studies utilizing a longitudinal design are needed to strengthen the evidence of a relationship with MEC on behaviors identified by cross-sectional studies especially with the correlate disordered eating behaviors and other potential child/adolescent correlates. The cross-sectional studies identified in the current review provide valuable insights into the associations between MEC and child/adolescent characteristics. However, due to the study design they are not able to show associations overtime and may be impacted by weaker evidence for a causal relationship.

More negative MEC was correlated with more disordered eating behaviors. All studies were conducted among adolescents and three studies used the same self-report measure of MEC. Future research 
is needed to examine the relationship between MEC and disordered eating behaviors for a wider ager range of children. Furthermore, as some associations for MEC and disorder eating behaviors were only found among girls, future studies are needed to examine how MEC is influenced by gender (White et al., 2014). Additionally, since there are gender differences among risk and protective factors, future studies should consider stratification as opposed to controlling for gender. Overall, more research is needed to examine the association between MEC and child temperament (Aviram et al., 2015), mealtime behavioral problems (Mitchell et al., 2004), aggression (Harbec \& Pagani, 2018), child prosocial behavior, sociometric ratings (Boyum \& Parke, 1995), depression (White et al., 2014), physical activity, and academic success (Harbec \& Pagani, 2018). These outcomes were only examined in one study each in terms of association with MEC and thus no conclusions could be drawn. Almost all these potential correlates were associated with indicators of MEC, but given the risk of study design bias, it is unclear whether these factors are truly linked to emotionality during mealtimes. In addition, children's physical activity, academic success and aggression show promising areas of future research as these were examined in a recent study using a longitudinal design (Harbec \& Pagani, 2018).

Among included studies, MEC was measured more commonly with direct observation of mealtimes than with parent or primary giver reported questionnaires. However, for direct observation only, three studies (the MICS; Berge et al., 2013; Czaja et al., 2011; Mitchell et al., 2004) used the same coding scheme to assess MEC, limiting our capacity to compare findings across studies. Based on the extant literature, we recommend that future studies consider validating a measure for observational coding of MEC while considering the existing measures' strengths, limitations, target age group and relevance of constructs with MEC. Specifically, the MICS coding scheme has strengths because it allows for direct observation in a natural family mealtime setting, it has been published more often than other coding schemes and validated through construct validity, and allows for coding of interactions occurring between all family members (Mitchell et al., 2009). Additionally, given that five of the seven sub-scales of MICS were directly correlated with MEC, future studies may consider using specific subscales of the MICS when coding for MEC. However, the MICS 
is related to overall family functioning and may not include relevant constructs related to MEC that are captured by other observational instruments. Specifically, the lowa Family Interaction Rating Scales (IFIRS), as adapted by Berge et al. (2014) is another promising measure because it captures relevant MEC constructs such as relationship quality, food hostility, and positive reinforcement. Further, while the MICS focuses on overall family functioning during mealtimes, IFIRS focuses on overall family dynamics in addition to individual parentchild dyads. While self-report measures also have merit, they have yet to be validated to measure MEC. In addition, given that MEC generally seems to be associated with some child or adolescent outcomes, the field needs a common definition and validated and reliable measures for MEC.

This review identified areas where future research would be most beneficial to advance the field of MEC research. As reported MEC has been measured across various age ranges. However, the body of literature examining MEC is lacking in terms of preschool outcomes. More research is needed to examine MEC in the preschool age group. This is an important age range to examine in terms of MEC as various transitions in mealtimes occur during this time- period. Additionally, preschool age is a formative period where children are developing their likes, dislikes, and nutrient intake patterns (Paroche et al., 2017; Skinner et al., 2002). While fostering positive MEC, parents and primary caregivers can offer a promising opportunity for young children to develop healthful eating behaviors that can transition into adolescence and adulthood.

Additionally, future research should examine factors that influence MEC. While the focus of the present study was to determine the correlates of MEC in healthy parents, studies have shown that parental disordered eating (Stein et al., 1994; Stein et al., 2006) and parental mental health such as depression, anxiety, obsessive-compulsive disorder, and chronic conditions such as diabetes can influence MEC (Harbec \& Pagani, 2018; Stein et al., 2006). Specifically, Stein et al. (1994) found that mothers who experienced eating disorders displayed more negative emotions during meals, more conflictual mealtimes, and their infants were at the lower end of the BMI percentile. In terms of parental mental health, Harbec and Pagani (2018) found that higher levels of maternal depression predicted lower quality of the family meal 
environment. One study found that lower parental BMI was correlated with dinner rituals that are attributes a positive MEC (Wansink \& van Kleef, 2014). However, another study found that less media usage and more dinnertime routines which are both aspects of a positive MEC were associated with child BMI but not parent BMI (Horning et al., 2017). Additionally, Wendt et al. (2015) found that MEC was not correlated with any maternal weight status or fathers who were obese or overweight. However, fathers who were overweight were more likely to control feeding during mealtimes (Wendt et al., 2015). In a study of families that were food insecure, more positive MEC was linked to lower emotional overeating for children (Eagleton et al., 2021). Therefore, given that this study has established a relationship between MEC and child dietary and weight outcomes, future studies are needed to address and better understand the role of factors such as parental mental and physical health as a distinct influence on MEC.

The current review was limited to articles published in English or an English translation was available. Thus, relevant international research on the topic may have been missed. Additionally, as a consistent definition of MEC is missing it may have led to exclusion of literature examining this topic. To address this limitation, a wide range of search terms were used to capture research examining emotions present during mealtimes. Additionally, publication bias and methodological issues in primary studies and article selection bias were limitations. These occurrences may have influenced the results of the current study such that previous studies did not find statistical significance between MEC and child outcomes may not have been published and thus were not included in the current examination. Additionally, due to selection bias all articles on the topic may not have been found in the databases to be included in the current review. Further, the present systematic review was unable to estimate the effect from each study as is done in a meta-analysis.

\section{Conclusions}

While no mutual definition or commonly identified measure of MEC was found, differing operationalizations has the potential to advance the field of work on MEC. As researchers are working with different 
data sets, age groups, settings, and may be interested in various aspects of MEC it is important for them to be able to operationalize MEC as it best attunes to their specific research question. In terms of the association between MEC and child outcomes, evidence is present for dietary intake, disordered eating behaviors and weight status/ BMI. Research suggests it is important to not only study the frequency of family meals but also the impact of MEC on children's physical activity, academic success, and aggression as mealtimes are a time to encourage communication, bonding, and monitoring (Harbec \& $\mathrm{Pa}$ gani, 2018). However, more research is needed to examine the impact of MEC on psychosocial child outcomes such as depression, temperament, and aggression. There is also a need for research examining MEC in the preschool age group, more longitudinal study designs, and outside the home setting.

Note The author's affiliation with The MITRE Corporation is provided for identification purposes only, and is not intended to convey or imply MITRE's concurrence with, or support for, the positions, opinions, or viewpoints expressed by the author. Approved for Public Release; Distribution Unlimited. Public Release Case Number 20-3051.

Funding sources This project is supported by the Betti and Richard Robinson Professorship and USDA National Institute of Food and Agriculture, Hatch project 1011204, and the Nebraska Agricultural Experiment Station (Dipti Dev PI). The USDA National Institute of Food and Agriculture had no role in the study design, collection, analysis or interpretation of the data, writing the manuscript, or the decision to submit the paper for publication.

Credit authorship contribution statement The first author conducted the literature search, data extraction, and risk of bias assessments. The first and third authors conducted the abstract and full-text screening. All authors contributed to the study design, protocol, writing, and editing of the manuscript. All authors have contributed to and approved the final manuscript.

Competing interest All authors declare that they have no conflicts of interest.

Acknowledgments The authors would like to thank Dr. Erica DeFrain for the database search and search strings, and Nicole Johnson, and Saima Hasnin for abstract screening and risk of bias assessment. We would also like to thank Dr. Madeleine Sigman-Grant for her contribution regarding scientific and technical writing. 


\section{References}

Aviram, l., Atzaba-Poria, N., Pike, A., Meiri, G., \& Yerushalmi, B. (2015). Mealtime dynamics in child feeding disorder: The role of child temperament, parental sense of competence, and paternal involvement. Journal of Pediatric Psychology. https://doi.org/10.1093/jpepsy/jsu095

Berge, J. M., Rowley, S., Trofholz, A., Hanson, C., Rueter, M., MacLehose, R. F., \& Neumark-Sztainer, D. (2014). Childhood obesity and interpersonal dynamics during family meals. Pediatrics, 134(5), 923-932. https://doi.org/10.1542/ peds.2014-1936

Berge, J. M., Jin, S. W., Hannan, P., \& Neumark-Sztainer, D. (2013). Structural and interpersonal characteristics of family meals: Associations with adolescent body mass index and dietary patterns. Journal of the Academy of Nutrition and Dietetics, 113 (6), 816-822. https://doi.org/10.1016/j.jand.2013.02.004

Birch, L. L., \& Fisher, J. O. (1998). Development of eating behaviors among children and adolescents. Pediatrics, 101(Supplement 2), 539-549.

Bland, J. M., \& Altman, D. G. (1997). Statistics notes: Cronbach's alpha. BMJ. https://doi.org/10.1136/bmj.314.7080.572

Boyum, L. A., \& Parke, R. D. (1995). The role of family emotional expressiveness in the development of children's social competence. Journal of Marriage and the Family. https://doi.org/10.2307/353915

Cassidy, J., \& Asher, S. R. (1992). Loneliness and peer relations in young children. Child Development. https://doi.org/10.1111/j.1467-8624.1992.tb01632.x

Chatoor, I., Getson, P., Menvielle, E., Brasseaux, C., O'Donnell, R., Rivera, Y., \& Mrazek, D. A. (1997). A feeding scale for research and clinical practice to assess mother-infant interactions in the first three years of life. Infant Mental Health Journal: Official Publication of The World Association for Infant Mental Health, 18(1), 76-91.

Cole, P., Wiggins, C., Radzioch, A., \& Pearl, A. (2007). D.O.T.S. Emotion coding system. Unpublished Manuscript. Department of Psychology, Pennsylvania State University.

Czaja, J., Hartmann, A. S., Rief, W., \& Hilbert, A. (2011). Mealtime family interactions in home environments of children with loss of control eating. Appetite. https://doi.org/10.1016/j.appet.2011.01.030

Dickstein, S., \& Martin, S. (2002). What's for dinner: Family functioning, maternal depression and early childhood outcomes. Zero to Three, 4, 21-28.

Dickstein, S., Hayden, L., Schiller, M., Seifer, R., \& San Antonio, W. (1994). Providence Family Study. Family mealtime interaction coding system. Unpublished coding manual. East Providence, RI: Brown University School of Medicine: Bradley Hospital. Bradley Research Center.

Eagleton, S. G., Na, M., \& Savage, J. S. (2021). Food insecurity is associated with higher food responsiveness in low-income children: The moderating role of parent stress and family functioning. Pediatric Obesity. https://doi.org/10.1111/ ijpo. 12837 
Eisenberg, M. E., Olson, R. E., Neumark-Sztainer, D., Story, M., \& Bearinger, L. $H$. (2004). Correlations between family meals and psychosocial well-being among adolescents. Archives of Pediatrics and Adolescent Medicine. https://doi. org/10.1001/archpedi.158.8.792

Fiese, B. H., Foley, K. P., \& Spagnola, M. (2006). Routine and ritual elements in family mealtimes: Contexts for child well-being and family identity. In Family mealtime as a context of development and socialization (pp. 67-89). https://doi. org/10.1002/cad

Fiese, B. H., Jones, B. L., \& Jarick, J. M. (2015). Family mealtime dynamics and food consumption: An experimental approach to understanding distractions. Couple and Family Psychology: Research and Practice. https://doi.org/10.1037/ cfp0000047

Fiese, B. H., \& Schwartz, M. (n.d.). Reclaiming the family table: Mealtimes and child health and wellbeing.

Fosco, G. M., \& Grych, J. H. (2013). Capturing the family context of emotion regulation: A family systems model comparison approach. Journal of Family Issues. https://doi.org/10.1177/0192513X12445889

Halberstadt, A. G. (1986). Family socialization of emotional expression and nonverbal communication styles and skills. Journal of Personality and Social Psychology, 51(4), 827.

Halberstadt, A. G., Cassidy, J., Stifter, C. A., Parke, R. D., \& Fox, N. A. (1995). Selfexpressiveness within the family context: Psychometric support for a new measure. Psychological Assessment. https://doi.org/10.1037/1040-3590.7.1.93

Harbec, M. J., \& Pagani, L. S. (2018). Associations between early family meal environment quality and later well-being in school-age children. Journal of Developmental and Behavioral Pediatrics. https://doi.org/10.1097/ DBP.0000000000000520

Hayden, L., Schiller, M., Dickstein, S., Seifer, R., Sameroff, A., \& Miller, K. (1998). Levels of family assessment I. Family, marital, and parent-child interaction. Journal of Family Psychology, 12, 7-22.

Horning, M. L., Schow, R., Friend, S. E., Loth, K., Neumark-Sztainer, D., \& Fulkerson, J. A. (2017). Family dinner frequency interacts with dinnertime context in associations with child and parent BMI outcomes. Journal of Family Psychology, 31 (7), 945-995. https://doi.org/10.1037/fam0000330

Hughes, S. O., Power, T. G., Papaioannou, M. A., Cross, M. B., Nicklas, T. A., Hall, S. K., \& Shewchuk, R. M. (2011). Emotional climate, feeding practices, and feeding styles: An observational analysis of the dinner meal in Head Start families. International Journal of Behavioral Nutrition and Physical Activity, 8. https://doi. org/10.1186/1479-5868-8-60

Jacobi, C., Hayward, C., De Zwaan, M., Kraemer, H. C., \& Agras, W. S. (2004). Coming to terms with risk factors for eating disorders: Application of risk terminology and suggestions for a general taxonomy. Psychological Bulletin. https://doi.org/10.1037/0033-2909.130.1.19

Jacobs, M., \& Fiese, B. (2007). Family mealtime interactions and overweight children with asthma: Potential for compounded risks? Journal of Pediatric Psychology, 32(1), 64-68. 
Janicke, D., Mitchell, M., \& Stark, L. (2005). Family functioning in school-age children with cystic fibrosis: An observational assessment of family interactions in the mealtime environment. Journal of Pediatric Psychology, 30(2), 179-186.

Kraemer, H. C., Kazdin, A. E., Offord, D. R., Kessler, R. C., Jensen, P. S., \& Kupfer, D. J. (1997). Coming to terms with the terms of risk. Archives of General Psychiatry. https://doi.org/10.1001/archpsyc.1997.01830160065009

Mitchell, M., Piazza-Waggoner, C., Modi, A., \& Janicke, D. (2009). Examining shortterm stability of the Mealtime Interaction Coding System (MICS). Journal of Pediatric Psychology, 34(1), 63-68.

Mitchell, M. J., Powers, S. W., Byars, K. C., Dickstein, S., \& Stark, L. J. (2004). Family functioning in young children with cystic fibrosis: Observations of interactions at mealtime. Journal of Developmental and Behavioral Pediatrics. https://doi. org/10.1097/00004703-200410000-00005

Moher, D., Liberati, A., Tetzlaff, J., \& Altman, D. G. (2009). Preferred reporting items for systematic reviews and meta-analyses: The PRISMA statement. BMJ, 339, b2535.

National Heart, Lung, and B. I. (2020). Study quality assessment tools. Retrieved February 6, 2020, from https://www.nhlbi.nih.gov/health-topics/ study-quality-assessment-tools

Neumark-Sztainer, D., Wall, M., Story, M., \& Fulkerson, J. A. (2004). Are family meal patterns associated with disordered eating behaviors among adolescents? Journal of Adolescent Health. https://doi.org/10.1016/j.jadohealth.2004.01.004

NIHR. (2019). PROSPERO. Retrieved October 15, 2019, from https://www.crd.york. ac.uk/PROSPERO/

Paroche, M. M., Caton, S. J., Vereijken, C. M. J. L., Weenen, H., \& Houston-Price, C. (2017). How infants and young children learn about food: A systematic review. Frontiers in Physiology. https://doi.org/10.3389/fpsyg.2017.01046

Partners, E. (2019). DistillerSR. Retrieved October 15, 2019, from https://www. evidencepartners.com/

Saltzman, J. A., Bost, K. K., Musaad, S. M. A., Fiese, B. H., Wiley, A. R., Strong, T., ... Fiese, B. (2017). Predictors and outcomes of mealtime emotional climate in families with preschoolers. Journal of Pediatric Psychology, 43(September 2017), 195-206. https://doi.org/10.1093/jpepsy/jsx109

Saltzman, J. A., \& Liechty, J. M. (2016). Family correlates of childhood binge eating: A systematic review. Eating Behaviors. https://doi.org/10.1016/j. eatbeh.2016.03.027

Skinner, J. D., Carruth, B. R., Bounds, W., \& Ziegler, P. J. (2002). Children's food preferences: A longitudinal analysis. Journal of the American Dietetic Association. https://doi.org/10.1016/S0002-8223(02)90349-4

Smith, J. A., Saltzman, J. A., \& Dev, D. A. (2019). Mealtime emotional climate and child health: a systematic review. PROSPERO CRD42019120135 Available from: https://www.crd.york.ac.uk/prospero/display record.php?ID=CRD42019120135

Stein, A., Woolley, H., Cooper, S., \& Fairburn, C. G. (1994). An observational study of mothers with eating disorders and their infants. Journal of Child Psychology and Psychiatry, 35(4), 733-748. 
Stein, A., Woolley, H., Cooper, S., Winterbottom, J., Fairburn, C. G., \& Cortina-Borja, M. (2006). Eating habits and attitudes among 10-year-old children of mothers with eating disorders. The British Journal of Psychiatry, 189, 324-329. https:// doi.org/10.1192/bjp.bp.105.014316

Tremblay, L., \& Rinaldi, C. M. (2010). The prediction of preschool children's weight from family environment factors: Gender-linked differences. Eating Behaviors. https://doi. org/10.1016/j.eatbeh.2010.07.005

Tynan, D., Miller, D., \& Chaiken, L. (2009). Eating and mealtime problems. Retrieved from https://www.nemours.org/content/dam/nemours/wwwv2/ filebox/service/health/parenting/tips/9eatingprob.pdf

Wansink, B., \& van Kleef, E. (2014). Dinner rituals that correlate with child and adult BMI. Obesity, 22(5), E91-E95. https://doi.org/10.1002/oby.20629

Wendt, V., Bergmann, S., Herfurth-Majstorovic, K., Keitel-Korndorfer, A., von Klitzing, K., \& Klein, A. M. (2015). Parent-child interaction during feeding or joint eating in parents of different weights. Eating Behaviors, 18, 131-136. Retrieved from https://doi.org/10.1016/j.eatbeh.2015.04.007

White, H. J., Haycraft, E., \& Meyer, C. (2014). Family mealtimes and eating psychopathology: The role of anxiety and depression among adolescent girls and boys. Appetite. https://doi.org/10.1016/j.appet.2014.01.007

White, H. J., Haycraft, E., \& Meyer, C. (2019). Family mealtime negativity and adolescent binge-eating: A replication and extension study in a community sample. Eating Behaviors. https://doi.org/10.1016/j.eatbeh.2019.101306

Zeller, M. H., Reiter-Purtill, J., Modi, A. C., Gutzwiller, J., Vannatta, K., \& Davies, W. H. (2007). Controlled study of critical parent and family factors in the obesigenic environment. Obesity. https://doi.org/10.1038/oby.2007.517 